SCIREA Journal of Animal Husbandry and Veterinary Medicine http://www.scirea.org/journal/AHVM

June 8, 2021

SCIREA

Volume 4, Issue 1, February 2021

\title{
CAMEL DROMEDARY TUBERCULOSIS: A REVIEW
}

\section{Dereje Teshome}

Oromia Agricultural Research Institute; Yabello Pastoral and Dryland Agriculture Research Center, P.O. Box 85, Yabello, Ethiopia

Email:derejeteshe@gmail.com

\begin{abstract}
Camel is an important species uniquely adapted to arid and semi-arid environments and contributes significantly to the food security of the nomadic pastoral households. Tuberculosis caused by Maycobacterium bovis is the most common form of tuberculosis in camels. The two known Mycobacteria causing Tuberculosis in camels are Maycobacterium bovis and Maycobacterium tuberculosis. Tuberculosis in dromedaries has been documented since 1888 and its geographic distribution is with great variations between regions and countries. Transmission of the disease is mainly occurs by inhalation. Infected animal introduced in to a non-infected herd act as a source infection. In advanced cases the signs of the disease are; weakness, erratic appetite, and emaciation as well as low grade fluctuating fever. Enlarged superficial lymph nodes provide a useful sign for diagnosis. A presumptive diagnosis of tuberculosis in camel is often made based on history, clinical findings, tuberculin skin tests, post-mortem, bacteriological and molecular techniques. Treatment is not advised for animals. Control depends on the removal of infected animals and prevention of further introduction of infection into the herd. Conventional cost intensive test-and-slaughter schemes do not appear to be appropriate control measures for animal tuberculosis in developing countries. Tuberculosis, as a zoonosis from camel to human which is caused by principal agent; M. bovis
\end{abstract}


plays an important role. In developing countries, the risk for contracting zoonotic tuberculosis is increased due to the higher infection rate in animals, absence of regular pasteurization of milk, cultural factors, poverty, malnutrition and a higher Human immune deficiency virus (HIV) infection rate. As a result, public awareness and appropriate control and prevention measures should be implemented to reduce the public health and economic burden of the disease. In general tuberculosis in animal as well as human is a challenging disease lack wide information on epidemiology, risk factors involved and role of M. bovis in human tuberculosis, so that significant further investigations are necessary for a better understanding of the disease; thus a better prevention and control of the infection in both animal and human.

Keywords: Camel dromedary, Review, Tuberculosis, Zoonosis.

\section{INTRODUCTION}

The dromedary camel (Camelus dromedarius) is an important livestock species adapted to hot and arid environments. It is most abundant in the arid lowlands of Africa, the Middle East and Western Asia. The economic importance of this multipurpose animal is evident from the numerous benefits provided by camel products (meat, milk, wool). Moreover, the camel serves for riding, as a beast of burden and as a draft animal for agriculture and transport (El Harrak et al., 2011).

Camels used in the development of camel dairy farms that are capable of producing camel milk on the commercial level. Camel milk and meat are considered an important source of proteins for wide range of population (Alhebabi and Alluwaimi, 2010). Camelus dromedaries have the ability to survive under harsh climatic conditions and have the potential to enhance pastoral household livelihoods under this distressful environment (Mahamed et al., 2015).

The Food and Agriculture Organization (FAO) estimates the total population of camel in the world today to be 25.89 million, of which $89 \%$ are Camelus dromedaries. Over $80 \%$ of the world's camel dromedary population is found in Africa with the highest concentration in North East Africa (FAO, 2013; Hussein et al., 2013; Sisay and Awoke, 2015).

In Ethiopia, Camelus dromedaries represent a subset of major livestock resources with the population estimated to be over one million. This number ranks the country third in Africa after Somalia and Sudan and fourth in the world (India included). The arid and semiarid areas 
of the country that constitute more than $60 \%$ of the total area and home of 7.8 million pastoral and agro-pastoral communities are suitable for camel production (Abebe, 2000).and play a significant multi-purpose role in transporting grain, water, salt and other goods as well as for milk and meat production (Abera et al., 2014). In recent years, camels have become one of the national export animals for Ethiopians (Kasaye et al., 2013). Camel also possess several attributes as minimum contribution to environmental degradation, utilization of scarce natural resources (feed and water), minimum competition with other ruminants and good adaptation to harsh environment (Abera et al., 2014). Thus camels have been indispensable alternative to cope up with the escalating rangeland ecological challenges (MOA, 2013).

Camels were formerly considered resistant to most of the diseases commonly affecting livestock; but as more research was conducted, camels were found to be susceptible to a large number of pathogenic agents (Abbas and Omer, 2006). There are a number of economically important diseases that affect camels (Dia, 2006).

Respiratory diseases are among the emerging problems of camels that are causing considerable loss in production and death (Zubair et al., 2004). Tuberculosis (Tb) is a chronic, contagious, granulomatous disease caused by mycobacterial species belonging to the Mycobacterium tuberculosis complex (MTC) (Thoen et al., 2006). Among Mycobacterial group Mycobacterium bovis (M. bovis) has a wide host range and is the most commonly reported causative agent of camel TB (Mamo et al. 2011). Tuberculosis caused by M. bovisis is the most common form of tuberculosis in camels (Dubie et al., 2016). The organism causes granulomatous abscesses in various tissues with a predilection for lymphoid tissues and lungs (Wernery and Kaaden, 2002).

Tuberculosis is a serious chronic infectious disease of humans and animals worldwide (Thoen et al., 2009; Ndukum et al., 2010). Tuberculosis, as a zoonosis from camel to human which is caused by principal agent; M. bovis plays an important role among nomadic people where milk and milk products are consumed raw (Seifert, 1992; Krauss et al., 2003).Moreover, close physical contact with their animals create a potential public health concern for transmission of zoonotic diseases such as tuberculosis (TB) from animals to the pastoralist (Mamo et al., 2011).In particular in pastoralists of the Horn of Africa where no treatment of milk is practiced either it is consumed raw or when it just soured (Zubair et al., 2004).

The camel rearing people are at high risk of contracting TB if their camels get infected by Mycobacterium species. Because, the society lack general awareness of TB and its zoonotic importance and family members share the same living house with their camels during the 
night time, there is high possibility of transmission of the infection between humans and camels. On top of that, only few of them have the habit of boiling milk before consumption. Raw camel milk consumer of the camel rearing society and their urban customers are in higher health risk (Beyi et al., 2014).

Tuberculosis in humans remains one of the major global reportable diseases, and a rise in its incidence has caused the World Health Organization (WHO) to declare the disease a global emergency. Therefore this review paper is done with the objectives: To review general information available on Camel (Camelus dromedaries) Tuberculosis and To forward recommendations toward the future study and investigations of camel Tuberculosis, control and prevention approaches.

\section{LITERATURE REVIEW}

\subsection{Definition}

Tuberculosis is a chronic, contagious, granulomatous disease caused by mycobacterial species belonging to the Mycobacterium tuberculosis complex (Wernery and Kinne, 2012). Tuberculosis caused by M. bovisis the most common form of tuberculosis in camels. The organism causes granulomatous abscesses in various tissues with a predilection for lymphoid tissues and lungs (Wernery and Kaaden, 2002).

\subsection{Etiology}

The genus Mycobacterium of the family Mycobacteriaceae includes non-motile and nonsporing acid-fast rods of various lengths. There are approximately 100 members of Mycobacterium genus and although most are saprophytic organisms that live in the environment. Some are strict parasites inhabiting the mucus membranes of their host and mycobacteria are cytochemical, Gram positive, the high lipid and mycolic acid content of their cell walls prevents uptake of the dyes employed in the gram stain (Quinn and Markey, 2003).

The following species are grouped in the MTC: M. tuberculosis, M. canettii, M. africanum, M. bovis,M. pinnipedii, M. caprae and M. microti; of these, M. tuberculosis, M. bovis, M.pinnipedii, M. capraeand M. microti have been isolated from camelids (Wernery and Kinne, 2012). Among Mycobacterial group Mycobacterium bovis (M. bovis) has a wide host range 
and is the most commonly reported causative agent of camel TB (Mamo et al. 2011). M. tuberculosis reported from tissue lesions (Zerom et al., 2012).

The causative agents of TB in Camel dromedaries are broadly classified as typical and atypical. The two most common Mycobacteria causing TB in camels are M. bovis and $M$. tuberculosis. Some of atypical Mycobacteria rarely causing TB in camels are M. kansassi, M. aquae, M. aquae var. ureolyticum, M. microti, M. fortuitum and M. smegmatis. The atypical species of Mycobacvterium cause disease in immune-compromised camel (Dubie et al., 2016). Bacterial species within the complex share $99.9 \%$ or greater similarity at a nucleotide level and have a virtually identical 16rDNA gene sequence. M.bovis is zoonotic, while infection with M.tuberculosis has been sporadically reported in domestic and wild animal species, most frequently in animals living in prolonged, close contact with humans (Ameni et al., 2010).

\subsection{Epidemiology}

There is little published information on the epidemiology of $\mathrm{Tb}$ specifically relating to camelids (Wernery and Kinne, 2012).Tuberculosis occurs worldwide in people, wild and domesticated or captive animals. Tuberculosis (TB) in dromedaries has been documented since 1888. The geographic distribution is with great variations between regions and countries (Kasaye et al., 2013).

Tuberculosis has been found worldwide. European Countries as well as the United States, Canada, Japan, and New Zealand reported a prevalence of bovine infection lower than $0.1 \%$. A few countries including Australia, Denmark, Sweden, Norway, and Finland are considered to be free of bovine tuberculosis. However the disease is endemic in all most all countries of Africa (Dubie et al., 2016).

Mustafa et al., (1987) mentioned in a brief review that disease was more commonly observed in farmed camels and those in close proximity to cattle but appeared to be rare among nomadic camels, suggesting that close contact facilitates transmission between domesticated animals. In 1991, Abdurrahman and Bornstein (1991) reported the disease to be relatively rare in Somalia, a country which at that time had one of the largest populations of old world camels (OWCs) in the world. Study on Tuberculosis outbreak in a dromedary racing herd up on rapid serological detection of infected camels a prevalence of $5.17 \%$ were reported by Wernery et al., (2007) as cited by Dubie et al., (2016).

Globally the status of camel tuberculosis reported from different countries. In the study conducted on 874 Bacterian camels in Russia they were 107 cases of tuberculosis resulting in 
$12.2 \%$ incidence rate, but only $68 \%$ of the camel with tuberculosis had positive tuberculin reaction. M. bovis strain was isolated from 46 pooled milk sample positive tuberculin reaction. M. bovis strains were isolated from 46 pooled milk samples from 712 lactating camel cows (kinne et al., 2006). Recently Wernery et al., (2007); described TB cases in dromedary in United Arab Emirates with typical lesion in both lungs. Outbreak in 58 camels of which 3 are infected with tuberculosis and the disease was confirmed at necropsy by finding gross lesion from $M$. bovis was isolated. Wernery et al., (2007) described TB cases in dromedary in United Arab Emirates with typical lesion in both lungs.

The study conducted in India on Pathology and diagnosis of Mycobacterium bovis in naturally infected dromedary camels (Camelus dromedarius) showed that a total of 18 (19.56\%) camels out of 92 examined based on gross lesions compatible with TB at post-mortem (Narnaware et al., 2015).

In Nigeria the prevalence of camel tuberculosis conducted in Northern Nigeria indicated prevalence of $17 \%$ of the 1395 animals tested showed positive reactions in the rapid test with a variable prevalence according to age and sex. The age of the animal was more important factor than sex for antibody detection rates recorded. Positive reactions increased significantly $(\mathrm{P}<0.05)$ with age (camels older than 10 years: 9.82\%) and more $(\mathrm{P}<0.05)$ females $(11.40 \%)$ than male camels showed positive test results (Caleb et al., 2012). prevalence of $22.6 \%$ of tuberculosis in slaughter camels (Camelus dromedarius) at Kano abattoir, Nigeria based on lateral-flow technology, also reported (Abubakar et al. 2014).

A cross sectional study of camel tuberculosis conducted in Ethiopia to describe its prevalence and isolate Mycobacterium bovis. In the study a total of 276 dromedary camels slaughtered at Dire Dawa abattoir and examined for the presence of gross tuberculosis lesions and further cultured to isolate Mycobacterium bovis. The study revealed 14 (5.07\%) prevalence based on postmortem examination (Mamo et al., 2009). Study in Ethiopian abattoirs has suggested a prevalence of $10.4 \%$, based on the identification of gross lesions in 906 apparently healthy camels (Mamo et al., 2011).

A recent cross sectional study was conducted on 420 apparently healthy camels slaughtered at Akaki abattoir to determine the prevalence of camel tuberculosis and to see its association with sex, age, and origin and body condition of camels. The study indicated the overall prevalence of $4.52 \%$ based on gross tuberculosis lesion detection; (Kasaye et al., 2013). Study conducted to investigate bovine tuberculosis in Camel dromedary in Eastern part of Ethiopia 
has also showed prevalence rate of $8.3 \%$ (33/398) based on the post mortem examination and $6.0 \%(29 / 480)$ at cut off $>4 \mathrm{~mm}$ based on the tuberculin test (Beyi et al., 2014).

\subsubsection{Host range and the role of reservoirs}

All species, including human beings, and age groups are susceptible to M. bovis with cattle, goat and pigs most susceptible and sheep and Horses showing a high natural resistance (Radostits et al., 2007). Although bovine tuberculosis was once found worldwide, control programs have eliminated or nearly eliminated this disease from domesticated animals in many countries (Srivastava et al., 2008).

In Northern America, the bison herds (Bison bison) have long been known to maintain $M$. bovis, and with elk (Cervus Canadensis). They provide an important reservoir in certain extensive range of conditions. In New Zealand, the brush tail possum (Trichosuron Vulpecula), and in England and Republic of Ireland, the badgers (Melesmeles), are implicated as significant reservoirs. In Africa, a reservoir of M. bovis is known to exist in Cape buffalo (Synceruscaffert, Lewchwe), the Cape kudu (Strep sicercus species) and Cape duiker (Sylvicaprospecies) (Dubie et al., 2016).

\subsubsection{Risk factors}

The host risk factor: all species including human beings, body conditions, sex and age groups are susceptible to M. bovis (Mamo et al., 2011). The occurrences of TB lesions in camels were relatively higher in the younger and older camels than other age groups which could be due to the fact that older animals have weaker immune system. The higher frequency of lesion in younger camels could be due to the less developed immunity (Menzies et al., 2000). Young camels can also be easily infected with higher doses of Mycobacteria via colostrum from infected camel in a similar way, as it occurs in cattle (Phillips et al., 2003). In connection with this, another report mentioned of vertical transmission of $M$. bovis from an infected dam to her calf through congenital infection in utero (Ozyigit et al., 2007). It was observed that lesion was more frequently observed in female camels as compared to male camels. This could be due to the fact that female camels were brought for slaughter at their older age after completion of the reproductive age (Munyeme et al., 2008) as cited in Dubie et al., (2016).

Also the pathogen risk factor: the causative organism is moderately resistant to heat, desiccation and many disinfectants; the virulence of M. bovis relates to its ability to survive and multiply in host macrophages. The environmental risk factor includes housing, sharing the same shelter with humans and the stocking intensity of animals (Quinn and Markey, 2003). 


\subsection{Source of Infection and Transmission}

There are different modes of spread of tuberculosis between camelid herds. One is the introduction of an infected animal into a non-infected herd (Bush et al., 1990). Secondly, animals with pulmonic lesions will excrete the organism in exhaled air, sputum and faeces from sputum that is swallowed (Windsor, 1999). The risk of being infected through aerogenous route is assumed to be high as there is a close association with camels since the livelihood of the over whelming nomadic population depend on camel. Camels in some countries (UAE) are no longer kept under nomadic management system and hence the risk zoonotic tuberculosis is increasing in those camels kept under intensive system of management (Wernery et al., 2007).

Tuberculosis is rare among camels kept under nomadic conditions. The disease occurs more frequently when camels are kept in close quarters with other camels or in close contact with cattle, for example in Russia and Egypt (Elmossalami et al., 1971; Donchenko et al., 1975). Pulmonary form of the TB is more common in camels indicating respiratory route as the major source of exposure in camel herds (Narnaware et al., 2015).

There is also other way to acquire the disease; for instance in the areas where dromedaries roam freely in the desert during day and return to their comps in evening; they can easily have contact with excretions of desert gazelles from which they contracted the infection. Several authors have reported tuberculosis in gazelles of the Arabian Peninsula (Ostrowski et al; 1998). It is also worthy of mention that dromedaries are coprophagus animals and this habit can expose them to the infectious agents (Dubie et al., 2016).

\subsection{Pathogenesis}

Tuberculosis spreads in the body by two stages, the primary complex and post primarily dissemination. The primary complex consists of the lesion at the point of entry and in the local lymph node. Post primary dissemination from the primary complex may take the form of acute miliary tuberculosis, discrete nodular lesions in various organs, or chronic organ tuberculosis caused by endogenous or exogenous reinfection of tissues rendered allergic to tuberculoprotein. Depending up on the site of localization of infection, clinical signs vary but, since the disease is always progressive, there is a constant underling toxemia which causes weakness, debility, and eventual death of host (Radostits et al., 2007).

Tuberculous lesions of cattle infected with M. bovis, most frequently found in the lungs and in the broncho-mediastinal lymph nodes, most probably in association with air-borne infection. 
In contrast to human infection, the primary pulmonary lesion in cattle rarely heals spontaneously, but tends to disseminate locally through the natural cavities, such as the bronchi, or more widely via the lymphatic and haematogenous routes. The outcome of the infection, with few exceptions, is a chronic wasting disease of long duration (Cosivi et al., 1995). In relation to distribution of the tuberculosis lesions in body organs, camels $57.14 \%$ of the tuberculosis lesions were localized in the lungs and associated lymph nodes, $28.57 \%$ in the retropharyngeal lymph nodes and $14.29 \%$ in the mesenteric lymph nodes (Kasaye et al., 2013). Enlarged mesenteric lymph node and caseous granulomatous lesions are indicated in figure 1
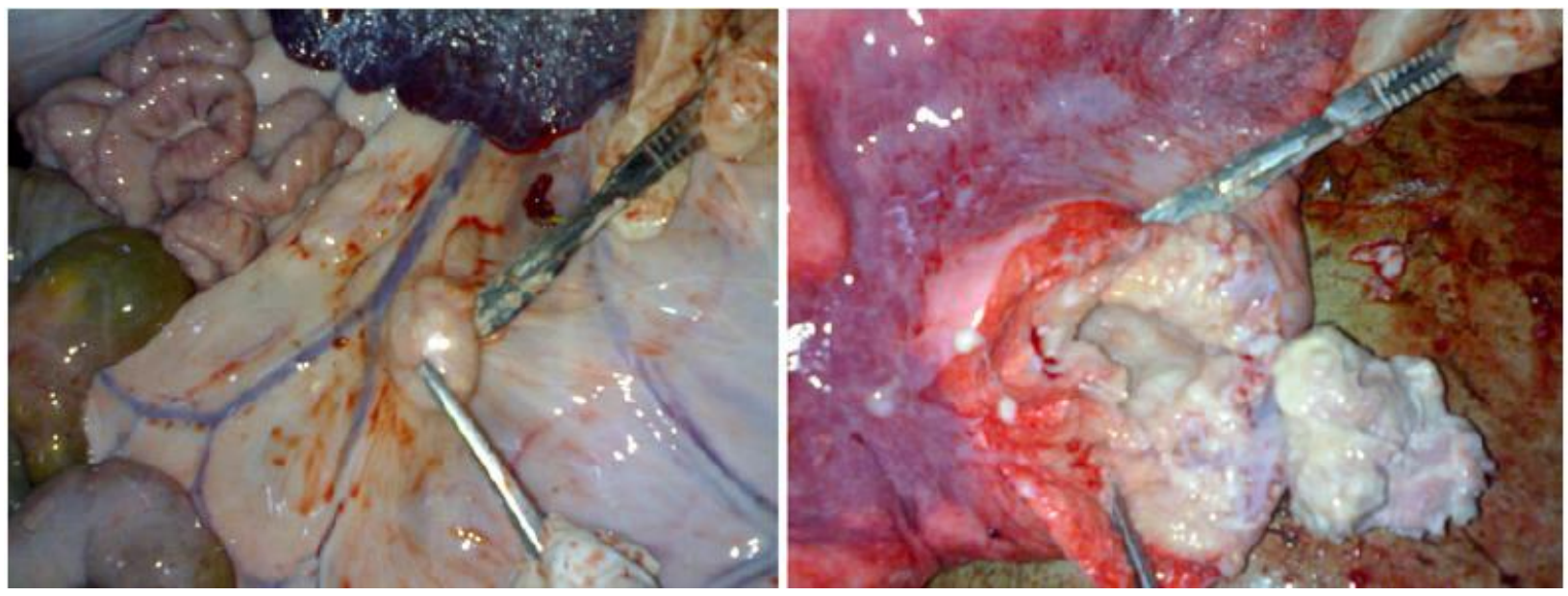

Figure 1: Granulomatous lesions from camel:

enlarged mesenteric lymph node (left) and cross section of a caseous granulomatous lesion in the lung (right). The mycobacterium isolated from this lesion was characterized as $\mathrm{M}$. tuberculosis (Photo: E. Meles). Source: (Gumi et al., 2012).

The histopathology of affected organs revealed typical granulomatous lesions where in the giant cells and acid-fast bacilli were occasionally observed in pulmonary form whereas they frequently observed in disseminated form (Narnaware et al., 2015).

\subsection{Clinical Findings}

Development of overt disease is often related to the virulence of the organism, the route of infection, the stage of infection and several host related factors. Regional lymph nodes may be enlarged in advanced cases and, in some instances, may rupture and drain to the surface (Smith, 2009). The general signs are: weakness, erratic appetite, and emaciations as well as low grade fluctuating fever. Enlarged superficial lymph nodes provide a useful diagnostic sign (Thoen et al., 1995). 
In advanced stages when much lung has been destroyed dyspnea with increased rate of respiration becomes apparent (Hirsh et al., 2004). Involvement of the mammary tissue may result in marked induration of affected quarters often accompanied by supra mammary lymph node enlargement (Quinn et al., 2002). Bovine TB manifests as a chronic granulomatous caseous necrotizing inflammatory process that primarily affects the lungs and their draining lymph nodes (Domingo et al. 2014).

Tuberculosis is a chronic debilitating disease. Clinical signs in camelids include; wasting, anorexia, respiratory distress, enlargement of superficial lymph nodes, recumbencey and eventually death. Clinical signs are often associated with extensive respiratory pathology, and it is surprising that overt respiratory distress is sometimes not observed in animals with severe lung lesions. Animals are occasionally found dead with no previous clinical observations (Wernery and Kinne, 2012).

\subsection{Diagnosis}

A presumptive diagnosis of TB in cattle and other susceptible species is often made on history, clinical findings, tuberculin skin tests, necropsy findings and other methods (OIE, 2009; Tessema et al., 2011). In vitro lymphocyte assays, including an interferon gamma assay and enzyme linked immunosorbent assays have been developed for the detection of the disease in cattle and so other animals exposed to M. bovis (Samuel, 2010). Diagnosis of TB in live camelids faces many difficulties (Wernery and Kaaden, 2002), with none of the currently available tests being able to detect disease with certainty. Schillinger (1987) reported false positive results of the skin test in $10-20 \%$ of Australian dromedaries. Culture is still internationally considered as the gold standard for detection of mycobacteria (Ayele et al., 2004). Mycobacterium is slow-growing and acid-fast organisms that usually appear on culture media within 2-6 weeks (Wernery and Kaaden, 2002). Mycobactrium bovis grows poorly in standard Lowensten-Jensen medium, one of the most widely used culture media (Grange, 2001).

During necropsy examination of the infected lesions varying from firm or hard white, grey, or yellow nodule with a yellow, caseous, necrotic center that was dry and solid to thin walled suppurative abscesses were classified as post mortem positive (Smith, 2009). Post mortem examination should be supported by histopathology and bacteriological examination of lesions for definitive diagnosis of BTB (OIE, 2004).

Microscopic examination using Zihel-Neelsen staining was directly done from tuberculosis suspected lesions. The stained slide were observed under a microscope for the presence of 
acid fast bacteria, which appear as red bacillary cells occurring singly or in clumps (Radostits et al., 2007).

The gamma interferon test (IFN- $\gamma$ ) and lymphocyte transformation assay are in vitro methods for measuring immune responses of circulating lymphocytes. The IFN- $\gamma$ test is acknowledged by the OIE as an alternative to the TST for internationally traded cattle but the currently used bovine IFN- $\gamma$ assay (Bovigam, Prionics, Switzerland) is unsuitable for camelids. The lymphocyte transformation assay is not used for routine diagnosis because it is time consuming and complicated to perform (Wernery and Kenni, 2012).

Multi-antigen print immunoassay (MAPIA) and the Vet TB Stat-Pak or 'rapid test' More recent serological tests include the (Waters et al., 2006). The MAPIA utilizes a range of antigens printed onto nitrocellulose strips that are incubated with serum samples; the rapid test is a portable lateral-flow chromatographic assay that uses three MTC-specific antigens. These antigens have shown some promise for detecting MTC-infected camelids, but further validation is still required before they can be used reliably for field diagnosis (Wernery et al., 2007).

Molecular techniques like polymerase chain reaction (PCR) and spoligotyping is also used. PCR is an in vitro DNA amplification method by enzymatic means at exponential rate that involves a repeated cycling process (Grainanger and Madden, 1993). It is a match faster method and reduces time for diagnosis for mycobacterium infections from 2 to 8 weeks to 2 days under controlled conditions and has shown sensitivity and specificity of nearly $90 \%$ in samples from respiratory organs (Pierle et al., 1991). Although the procedure is very sensitive when used on tuberculosis culture, similar levels of detection are not observed for clinical samples. It also detects culture negative samples that contained no microscopically visible acid fast organisms (Wards et al., 1995). The spoligotyping (spacer oligonucleotide typing) is one of the recently developed techniques, which has been developed to aid the differentiation of isolates belonging of the M. tuberclosis complex, including M. bovis. It is known for its use in the epidemiological investigation of TB, which improves the traceability of the infection or origin of outbreaks and it is presently considered as promising techniques (Kamerbeek et al., 1997).

\subsection{Treatment}

First lines of drugs for TB therapy are streptomycin, isonized (INH), ethambutol and rifampin. Second line drugs are phyazinamide, paraminosalicylic acid, kanamycin, cyclosserine, 
caperomycin and ethionamide. Because of resistance often develops under single drug regime a combination is commonly used. Because of the public health hazards inherent in the retention of TB animals, anti-tuberculous chemotherapy of animals is discouraged (Hirsh and Zee, 1999). The drug is not advised for animals because of long term treatment, which is uneconomical except for high yielding animals (Radostits et al., 2000).

\subsection{Control and Prevention}

Effective control requires an understanding of epidemiology of infection within the ecological system that can include domestic as well as wild animal species (Cousins, 2001). Control of bovine TB in livestock and wildlife species relies on timely detection and removal or slaughter of infected animals and/or herds. In camelids, this strategy is difficult to conduct because of the lack of adequate tests for live animals (Wernery et al., 2007).

The basic strategies required for control and elimination of bovine tuberculosis are well known and well defined. However, because of financial constraints, scarcity of trend professionals, lack of political will, as well as the underestimation of the importance of zoonotic TB in both the animal and public health sectors by national governments and donor agencies, control majors are not applied or are applied inadequately in most developing countries. Measures to prevent transmission of infection should be the primary objective to be achieved with trained public health personnel, public education and proper hygienic practices (Cosivi et al., 1998).

Eradication is common in herds and areas which have low incidence of the disease. When the incidence of the tuberculosis is high, a routine test and slaughter program may be economically impossible. Alternatively, vaccination may be used as temporary measure (Radostits et al., 2007).

In developing countries, however, BTB remains a major animal health problem, mainly because these countries cannot shoulder the financial burden required to implement a control programme and compensate for slaughtered animals. Limited access to education, poor information network and lack of disease surveillance are other factors that limit the implementation of any such programmes (Ayele et al., 2004). Vaccine is not yet available for camels (Wernery and kinne, 2012).

\subsection{Zoonotic Importance of Camel Tuberculosis}

Tuberculosis (TB) is among the most devastating human infectious diseases worldwide. An estimated 8.8 million new cases, a global average incidence rate of $128 / 100,000$ 
population/year, and 1.5 million deaths were attributed to TB in 2010 (WHO, 2011). The current increasing incidence of tuberculosis in humans, particular in immune compromised human, has given renewed interest in the zoonotic importance of M. bovis, especially in developing countries (Radostits et al., 2007).

Human TB is caused principally by M. tuberculosis. The main causative agents of bovine TB are $M$. bovis and, to a lesser extent, M. caprae; however, zoonotic transmission of these pathogens is well described and occurs primarily through close contact with infected cattle or consumption of contaminated animal products such as unpasteurized milk (Ayele et al., 2004). In pastoral communities of Afar, Somali and Borana, camels are kept almost entirely for milk production. In these communities, camel milk is consumed raw, and this habit combined with close physical contact with their animals create a potential public health concern for transmission of zoonotic diseases such as TB from animals to the pastoralist (Mamo et al., 2011).

In general camel tuberculosis similar to bovine tuberculosis results a serious zoonotic impact especially in nomadic population where consumption of raw camel milk and animal products remain the common practice (Mamo et al., 2011). Tuberculosis, as a zoonosis from camel to human also plays an important role among nomadic people where milk and milk products are consumed raw (Seifert, 1992).

The presence of multiple additional risk factors can affect the zoonotic aspects of M. bovis in Africa. Risk factors such as human behavior, close physical contact between humans and potentially infected animals, habit of consumption of raw milk, which is widely practiced and increasing incidence of HIV infection which is closely linked with tuberculosis (Michel et al., 2010; Muller et al., 2013). HIV/AIDS is thought to facilitate transmission and progression to active disease of any form of TB (LoBue et al., 2003).

Ethiopia ranks seventh among the world's 22 countries with high tuberculosis (TB) disease burden and had an estimated incidence rate of 379 cases per 100,000 people per year (WHO, 2008). In Ethiopia, M. bovis was found to be a cause for tuberculous lymphadenitis in $17.1 \%$ of 29 human tuberculosis cases (Kidane et al., 2002). Also in Ethiopia, Shitaye et al., (2007) reported that $16.7 \%$ of 42 human isolates were identified as M. bovis. These findings show that the role of $M$. bovis in causing human tuberculosis seemed to be significantly important. 


\subsection{Status of Camel Tuberculosis in Ethiopia}

Ethiopia is one of the African countries where BTB is considered as protruding disease in animals. Detection of BTB in Ethiopia is carried out most commonly on the basis of tuberculin skin testing, abattoir meat inspection and rarely on bacteriological techniques (Shitaye et al., 2007). In general, there is scanty information on TB in camels. Nonetheless, there are few reports published on camel TB in Ethiopia as well as in other countries. The prevalence of camel TB currently recorded at Akaka and Metehara abattoirs was 10.04\% (91/906) on the basis of pathology and it was significantly higher in females .The tropism of TB lesions was significantly different among the lymph nodes and lung lobes. Mycobacterium growth was observed in 34\% (31/91) of camels with grossly suspicious TB lesions (Hussein, 2009).

Although, the extent of TB has been well documented in humans and most domestic animals, very little is known about the pathology and cause of camel TB in pastoral areas of the world. In Ethiopia, there are some studies indicating the existence of camel TB with a prevalence of camel TB ranges from 5.07\% in Dire Dawa abattoir (Mamo et al., 2009) to 12.3\% in Eastern Etiopia abattoir based (Zerom et al., 2012) as summarized in (Table 1).

Table 1: Summary of Status of Camel Dromedary Tuberculosis in Ethiopia.

\begin{tabular}{ccc}
\hline Title and site of the study & Reported Prevalence & Authors \\
A cross sectional study of camel tuberculosis in & $5.07 \%$ based on postmortem & Mamo et al., 2009 \\
Ethiopia at Dire Dawa abattoir & examination & Hussein, 2009 \\
Study on Mycobacterium tuberculosis complex & $34 \%(31 / 91)$ of camels with & grossly suspicious TB lesions \\
infection in livestock and humans in Amibara & & Mamo et al., 2011 \\
District of Afar Region & of pathology & \\
Pathology of camel tuberculosis and molecular \\
characterization of its causative agents in pastoral \\
regions of Ethiopia at Akaki and Metehara abattoirs \\
$\begin{array}{c}\text { Tuberculosis in dromedaries in Eastern Ethiopia: } \\
\text { Abattoir-based prevalence and molecular typing of } \\
\text { its causative agents }\end{array}$
\end{tabular}


Prevalence of bovine tuberculosis in dromedary

camels and awareness of pastoralists about its zoonotic importance in Eastern Ethiopia in in Dire

Dawa City Administrative Council (DDAC) and Somali pastoral region from

$8.3 \%$ based on the post mortem examination and $6.0 \%$ based on the tuberculin

Beyi et al., 2014

test

\section{CONCLUSION AND RECOMMENDATIONS}

This review revealed that different finding of conducted research on camel tuberculosis and its public health implications indicated the role of the disease is significantly important. Camel Tuberculosis has significant effect both in animals and humans in areas where control of the disease is not implemented and consumption of uncooked products of camel is adopted. The status of the disease is not well known and people have little or no awareness on the potential risk of the disease as zoonosis. Pastoralists who are closely tied with rearing of camels are at risk of being infected with zoonotic disease such as camel tuberculosis. Peoples consuming of raw infected camel milk, having close association with infected animals have high probability of being acquiring the infection. Conventional cost intensive test-andslaughter schemes do not appear to be appropriate control measures for animal tuberculosis in developing countries. Based on the above conclusive remarks, the following recommendations are forwarded:

In Camel rearing countries future research should be promoted on further investigating camel tuberculosis in mostly affected areas for understanding of its epidemiological status so as to design a control strategy.

$>$ Feasible control strategies for camel tuberculosis in developing countries need to be designed.

$>\quad$ Awareness creation about camel Tuberculosis, transmission path way, prevention and control methods, as well as its zoonotic importance for peoples in camel rearing areas to reduce the risk of transmission and infection of humans by M. bovis.

Public awareness on implementation of pasteurization of milk before consumption and detailed meat inspection in abattoir.

$>$ Implementation of one health approach for Zoonotic camel tuberculosis control. 


\section{REFERENCES}

[1] Abbas B. and Omer H. (2006): "Review of infectious diseases of the camel". Animal Science. Data base, CABI Publishing.

[2] Abdurahman, O.S. and Bornstein, S. (1991): Diseases of camels (Camelus dromedarius) in Somalia and prospects for better health. Nomadic Peoples., 29: 104-112.

[3] Abebe, D. (2000): Pastoralism and Pastoral Production System. In: Proceeding of the Ethiopian Society of Animal Production (ESAP). August 2000. Addis Ababa, Ethiopia, pp. $1-5$.

[4] Abera, D., Birhanu, T., Baker, T. (2014): Prevalence of Camel trypanosomosis at Selected Districts of Bale Zone, Southern Ethiopia. Sci. Technol. Arts Res. J.; 3(3): 103106.

[5] Abubakar, U.B., Kudi, A.C., Abdulkadri, I.A. and Okaiyeto, S.O., 2014. Prevalence of tuberculosis in slaughter camels (Camelus dromedarius) at Kano abattoir, Nigeria based on lateral-flow technology. Journal of Camel Practice and Research., 21: 41-45.

[6] Alhebabi, A.M. and Alluwaimi, A.M. (2010): Paratuberculosis in Camel (Camelus dromedarius): The Diagnostic Efficiency of ELISA and PCR. Open Veterinary Science Journal., 4: 41-44.

[7] Ameni, G., Vordermeier, M.B., Firdessa, R.C., Aseffa, A.C., Hewinson, G.B., Gordon, S.V. and Berg, S. (2010): Mycobacterium tuberculosis infection in grazing cattle in central Ethiopia. The Vet. J., 188:359-361.

[8] Ayele, WY., Neill, SO., Zinsstag, J., Weiss., MG., Pavlic, I. (2004): Bovine tuberculosis: an old disease but a new threat to Africa. Int. J. Tuberc. Lung Dis. 8: 924-937.

[9] Beyi, A.F., Gezahegne, K.Z., Mussa, A., Ameni, G. and Ali, M.S., 2014. Prevalence of bovine tuberculosis in dromedary camels and awareness of pastoralists about its zoonotic importance in Eastern Ethiopia. Journal of Veterinary Medicine and Animal Health., 6: $109-115$.

[10] Bush, M., Montali, R., Philipps, L. and Holobaugh, P. (1990): Bovine tuberculosis in Bacterian camel herd: clinical, therapeutic and pathogenic finding. J. Zoo wildlife Med., 21: $71-179$.

[11] Caleb, K., Abubakar, B. and Awah, N. (2012): Prevalence of bovine tuberculosis in camels in Northern Nigeria. Journal of Camel Practice and Research., 19:81-86. 
[12] Cosivi O., Meslin F.K., Daborn C.J., Grange J.M. (1995):The epidemiology of Mycobacterium bovis in infections in animals and humans, with particular reference to Africa. OIE Scientific and Technical Review, 14: 733-746.

[13] Cosivi, O.,Grange, J.M., Dabora, C.J., Ravighone, M.C., Fujikura, T., Cousins, D., Robinsen, R.A., Huchzermeyer, .A.K., deKantor, I. and Mesilin, F-X. (1998): Zoonotic tuberculosis due to Mycobacterium bovis in developing countrys.ImergingInfectios Diseases, 4:1-14.

[14] Cousins D.V. (2001): Mycobacterium bovis infection and control in domestic livestock. Rev Sci Tech. Apr;20(1):71-85.

[15] Dia, M.L. (2006): Parasites of the camel in Burkina Faso. Trop. Anim. Hlth., Prod., 38: $17-21$.

[16] Domingo, M., Vidal, E. and Marco, A. (2014): Pathology of bovine tuberculosis, Research in Veterinary Science., 97: 20-29.

[17] Donchenko, A. S.; Donchenko, E. A.; Fatkeeva, E. A. and Kibsov. (1975): "Isolation of tuberculosis mycobacteria in camel milk, their survival in shubat and methods of decontamination of these products. Vest. Sel. Khoz, Nauk, Alma., 4:119-122.

[18] Dubie, T., Sisay, T., Zeru, F., Gebru, M., Negash, W. (2016): Preliminary assessesment on the epidemiology and Public health implication of camel tuberculosis in Pastoral area of Ethiopia. World Journal of Pharmaceutical Research, 5: 94-115.

[19] El Harrak, M., Faye, B. and Bengoumi, M. (2011): Main pathologies of camels, breeding of camels, constraints, benefits and perspectives. The OIE Regional Conference for the Middle East, Beirut, Lebanon, 3-6 October 2011.

[20] Elmossalami, E., Siam, M. E. and Sergany, M. (1971): Studies on tuberculosis-like lesions in slaughtered camels. Zentralblatt for Veterinary medicine., 18: 253-261.

[21] FAO (2013): Statistical year book.Food and Agriculture Organization of the United Nations, Rome, Italy, 2013.

[22] Grainanger, J. and Madden, D., 1993. The polymerase chain reaction: turning needles into haystacks. Biologist.; 5: 197-200.

[23] Grange, J.M. (2001): Mycobactrium bovis infection in human beings. Vet. Microbiol., 40:71-77.

[24] Gumi, B., Schelling, E., Berg, S., Firdessa, R., Erenso, G., Mekonnen, W., Hailu, E., Melese, E., Hussein, J., Aseffa, A., Zinsstag, J. (2012): Zoonotic transmission of tuberculosis between pastoralists and their Livestock in southeast Ethiopia. Econ. Health 9:139-149. 
[25] Hirsh, A., Tsolaki, A., DeRiemer, K., Feldman, M., Small, P. (2004): Stable association between strains of Mycobacterium tuberculosis and their human host populations. Proceedings of the National Academy of Sciences of the United States of America., 101:4871-4876.

[26] Hirsh, D.C. and Zee, Y.C. (1999): Veterinary Microbacterium. $1^{\text {st }}$ ed, USA: Blackwell Science. Pp. 163-164.

[27] Husein, A., Haftu, B., Hunde, A. and Tesfaye, A. (2013): Prevalence of camel (Camelus dromedaries) mastitis in Jijiga Town, Ethiopia. African Journal of Agricultural Research., 8: $3113-3120$

[28] Hussein, N. (2009); Study on Mycobacterium tuberculosis complex infection in livestock and humans in Amibara District of Afar Region. MSc Thesis, Addis Ababa University, Faculty of Veterinary Medicine, Debre-zeit, Ethiopia.

[29] Kamerbeek, J.L., Schous, A., Kolk, M., Argemed, D., Vansooligeten, S., Juijiper, A., Buschoten, H., Movizen, R., Goyal, M. and Van Embden, J. (1997): Simultaneous detection and differentiation of Mycobacterium tuberculosis for diagnosis and epidemiology. J. clin.Microbiol., 35: 1907-1914.

[30] Kasaye, S., Molla, W. and Amini, G., 2013. Prevalence of camel tuberculosis at Akaki abattoir in Addis Ababa, Ethiopia. African Journal of Microbiology Research., 7: 21842189.

[31] Kidane, D., Olobo, JO., Habte, A., Negesse, Y., Aseffs, A., Abate, G., Yassin, MA., Betreda, K., Harboe, M. (2002): Identification of the causative organism of tuberculosis lymphadenitis in Ethiopia by PCR. J. Clin. Microbiol., 40: 4230-4234.

[32] Kinne, J., Johnson, B., Jahans, K.L., Smith, N.H., Ul-Haq, A. and Wernery, U. (2006): Camel tuberculosis a case report. Trop. Anim. Health Prod., 38, 207-213.

[33] Krauss, H. Schiefer, HG. Weber, A. Sclenczka, W. Appel, M. Graeventiz, AV. Enders, B. Zahner, H. Isenberg, DH. (2003): Zoonoses book: Infectious disease Transmissible from animals to Humans. 3rd ed. Washington DC: AM press, pp. 209-211.

[34] LoBue, PA., Betacourt, W., Peter, C., Moser, KS. (2003): Epidemiology of Mycobacterium bovis disease in San Diego County, 1994-2000. Int J Tuberc Lung Dis., $7: 180-5$.

[35] Mahamed, A Haji, A. Beriso, K Gebeyew, K. (2015): Small Holder Camel Milk Production Performance in Jigjiga District, Somali Regional State, Eastern Ethiopia. $J$ Veterinar Sci Technol., 6: 267. doi:10.4172/2157-7579.1000267. 
[36] Mamo, G. Kassaye, A. Sanni, M. Ameni, G. (2009): A cross sectional study of camel tuberculosis in Ethiopia. Bull. Anim. Health Prod. Afr., 57: 13-20.

[37] Mamo, G., Bayleyegn, G., Tessema, T. S., Legesse, M., Medhin, G., Bjune, G., Abebe, F. and Ameni, G. (2011): Pathology of camel tuberculosis and molecular characterization of its causative agents in pastoral regions of Ethiopia. Public Lib. Sci., One 6(1): e15862. doi:10.1371/journal.pone.0015862.

[38] Menzies, F. and Neill, S. (2000): Cattle to Cattle transmission of bovine tuberculosis. Vet. $J$, 160: 92-106.

[39] Michel, AL., Muller, B., Van Helden, PD. (2010): Mycobacterium bovis at the animalhuman interface: a problem, or not? Vet Microbiol., 140:371-81.

[40] Ministry of Agriculture (MOA), (2013): Draft document on the establishment of Diseasefree zones, Ministry of griculture, Ethiopia, pp: 23.

[41] Müller, B., Dürr, S., Alonso, S., Hattendorf, J., Laisse, CJM., Parsons, SDC., et al. ( 2013): Zoonotic Mycobacterium bovis-induced tuberculosis in humans. Emerg Infect Dis [Internet]. Jun [date cited]. http://dx.doi.org/10.3201/eid1906.120543.

[42] Munyeme, M., Muma, J., Skjerve, E., Nambota, A. and Phiri, I.(2008): Risk Factors Associated with Bovine Tuberculosis in Traditional Cattle of the Livestock/Wildlife Interface Areas in the Kafue Basin of Zambia. Prev Vet Med, 85: 317-328.

[43] Mustafa I.E. (1987): Bacterial diseases of dromedaries and bactrian camels. Rev. sci. tech. Off. int. Epiz., 6 (2), 391-405.

[44] Narnaware, SD., Dahiya, SS., Tuteja, FC., Nagarajan, G., Nath, K., Patil, NV. (2015): Pathology and diagnosis of Mycobacterium bovis in naturally infected dromedary camels (Camelus dromedarius) in India. Trop Anim Health Prod., 47(8):1633-6. doi: 10.1007/s11250-015-0905-5.

[45] Ndukum, A., CalebKudi, A., Bradley, G., Ane- Anyangwe, I.N., Fon-Tebug, S. and Tchoumboue, J. (2010): Prevalence of bovine tuberculosis in abattoirs of the littoral and western highland regions of Cameroon: a cause for public health concern, SAGEHindawi Access to Research. Veterinary Medicine International Article ID 495015, doi: $10.4061 / 2010 / 495015$

[46] Office of international des epizootics (OIE) (2009): Bovine Tuberculosis. World organization for animal health manual of diagnostic tests and vaccines for terrestrial animals (mammals, birds and bees). 6th Edition, Paris, Pp. 1-16. 
[47] Office of international des epizootics (OIE). (2004): Bovine tuberculosis; In manual of diagnostic tests and vaccines for terrestrial animals (mammals, birds and bees). $5^{\text {th }}$ ed. World organization for animal health, Pp. 451-463.

[48] Osrowski, S., Bedin, E., Lenain, M. and Auzinada, H. (1998): Ten years of Arabian achievements and regional perspective. Oryx, 32: 209.

[49] Ozyigit, M., Senturk, S. and Akkoc, A. (2007): Suspected Congenital Generalized Tuberculosis in a Newborn Calf. Vet Rec., 160: 307-308.

[50] Phillips, C., Foster, C., Morris, P and Teverson, R. (2003): The Transmission of Mycobacterium bovis Infection in Cattle. Res Vet Sci., 74: 1-15.

[51] Pierle, C., Lecossier, D., Boussovgant, Y., Bocart, D., Joly, V. and Hance, A.J. (1991): Use of amplification protocol improves sensitivity of detection of mycobacterium bovis in clinical sample by amplification of DNA. J. Clin. Microbiol., 29:712-717.

[52] Quinn, J.P., Carter, M., Donnelly, C.J.W. and Leonard, C.F. (2002): Veterinary Microbiology and Microbial Diseases. $1^{\text {st }}$ ed, Great Britian: Blackwell Science. Pp. 113118.

[53] Quinn, JP, Markey, BK (2003): Concise review of veterinary microbiology. 2nd Ed. USA: Blackwell publishing, pp. 34-35.

[54] Radostits, O., Gay, C., Blood, D. and Hinchclif, K. (2007): Veterinary medicine. A text book of the disease of cattle, sheep, pigs, goats and horses. $10^{\text {th }}$ ed. London, Saunder Elsevier. Pp.471-500.

[55] Radostits, O.M., Gay, C.C., Blood, D.C. and Hinchcliff, K.W. (2000): Deborah Russell (ed). Atext book of the diseases of Cattle, Sheep, Goat and Horses, $9^{\text {th }}$ ed. Harcout Publishers Ltd, London. Pp.909-919.

[56] Samuel, K. A. (2010): Molecular characterization of mycobacterial species isolated from tuberculous lesions seen in bovine carcasses at postmortem: a case study of three abattoirs in the Accra Region of Ghana. A thesis Master of Science, Ghana.

[57] Schillinger, D. (1987): Camel (Camelus dromedarius). Seminarson derdruck Vet. Labhard Verlag Konstanz., 9;50-53.

[58] Seifert, H.S.H. (1992): Tropentierhygiene, (Gustav Fischer Verlag, Jena), p.285-289.

[59] Shitaye, JE., Tsegaye, W., Pavlik, I. (2007): Bovine tuberculosis infection in animal and human populations in Ethiopia: A review. Vet. Med., 52(8): 317-332.

[60] Sisay, F. and Awoke, K. (2015): Review on Production, Quality and Use of Camel Milk in Ethiopia. J Fisheries Livest Prod., 3: 145. 
[61] Smith, B.P. (2009): Large animal internal medicine $.4^{\text {th }}$ ed. Mosby, inc, an affiliate of Elsevier inc. p.873-897.

[62] Srivastava, K., Chaouhan, D.S., Gupta, P., Singh, H.B., Sharma, V.D., Yadar, F., Sreekumaran, V.S., Thakari, S.S., Dharamadhee, J.S., Nigam, P., Prasad, H.K. and Katoch, V.M. (2008): Isolation of Mycobacterium bovis and Mycobacterium tuberculosis from catlle of some farming in North India: possible relevance in human health. Indian J. Med. Reser., 1: 10-12.

[63] Tessema, B., Beer, J., Emmrich, F., Sack, U. and Rodloff, A.C. (2011): Rate of Recovery of Mycobacterium tuberculosis from Frozen Acid-Fast-Bacillus Smear-Positive Sputum Samples Subjected to Long-Term Storage in Northwest Ethiopia. JCLIMICR., 49: 25572561.

[64] Thoen C.O., LoBue P.A. \& de Kantor I. (2006): The importance of Mycobacterium bovis as a zoonosis. Vet. Microbiol., 112 (2-4), 339-345.

[65] Thoen, C.O., Lobue, P.A., Enarson, D.A., Kaneene, J.B. and de Kantor, I.N. (2009): Tuberculosis: a re-emerging disease in animals and humans. Veterinari Italiana., 45: 135181.

[66] Thoen, O.C. and Steele, J.H. (1995): Mycobacterium bovis infection and transmission in humans and animals. Iowa state University press. Ame ., 24: 15-165.

[67] Wards, B.J., Collins, D.M. and Delsile, G.W. (1995): Detection of Mycobacterium bovisin tissues by polymerase reaction. Vet. Microbio. p. 227-240.

[68] Waters, W.R., Palmer, M.V., Thacker, T.C., Bannantine, J.P., Vordermeier, H.M., Hewinson, R.G., Greenwald R., Esfandiari J., McNair J., Pollock J.M., Andersen P. \& Lyashchenko, K.P. (2006): Early antibody responses to experimental Mycobacterium bovis infection of cattle. Clin. vaccine Immunol., 13 (6), 648-654.

[69] Wernery, U and Kaaden, OR. (2002): Infectious diseases of camelids. Blackwell Science, Berlin, pp. 23-373.

[70] Wernery, U. and Kinne, J. (2012): Tuberculosis in camelids: a review. Rev.sci. tech. Off. int. Epiz., 31 (3): 899-906

[71] Wernery, U., Kinne, J., Jahans, K.L., Vordermeier, H.M., Esfandiari, J., Greenwald, R., Johnson, B., Ul-Haq, A. \& Lyashchenko K.P. (2007): Tuberculosis outbreak in a dromedary racing herd and rapid serological detection of infected camels. Vet. Microbiol., 122 (1-2): 108-115.

[72] Windsor, R. (1999): Bovine tuberculosis in alpacas and llamas. Proceed. Bri. Vet Camelid Soc. Penrith, UK, Pp 32-34. 
[73] World Health Organization. (2008): Profiles of High-Burden Countries, Geneva: Switzerland, World Health Organization.

[74] World Health Organization. (2011): Global tuberculosis control. WHO Report. Geneva: The Organization.

[75] Zerom, K., Tesfaye T., Mamo, G., Bayu, Y. and Ameni, G. (2012): Tuberculosis in dromedaries in Eastern Ethiopia: Abattoir-based prevalence and molecular typing of its causative agents. Small Rumin. Res., 109: 188-192.

[76] Zubair, R., Khan, A.M.Z. and Sabri, M.A. (2004): Pathology of Camel Lungs. J. of Camel Scien., 1:103-106. 